\title{
AS INTERFACES DA VULNERABILIDADE SOCIAL DE IMIGRANTES E REFUGIADOS FRENTE A COVID-19: CENÁRIO MATO-GROSSENSE
}

\author{
Kelly PELLIZARI ${ }^{1}$ \\ Henrique Roriz Aarestrup ALVEZ ${ }^{2}$
}

RESUMO: O objetivo deste estudo consiste em avaliar os impactos da pandemia de Covid-19 sobre a população imigrante e refugiada em Mato Grosso. A situação de vulnerabilidade social tem se agravado com o aumento das desigualdades socais em meio a pandemia. Mato Grosso, onde a falácia de "estado agrícola rico" não se configura como uma realidade para todos, teve um aumento considerável de imigrantes na última década que, ao tentarem se inserir socialmente, deparam-se com os mais variados desafios. Os caminhos metodológicos se inscrevem na perspectiva qualitativa; utilizando o método bola de neve, coletou-se os dados de 30 imigrantes e refugiados que foram submetidos a uma análise de conteúdo com viés interpretativista - não limitando-se apenas aos enunciados. Os principais resultados apontam que a pandemia intensificou a situação de vulnerabilidade social de imigrantes e refugiados em Mato Grosso, e que a vulnerabilidade social apresenta diferentes interfaces, tais como: econômica, sanitária, jurídica, psicológica, entre outras náo exploradas no estudo.

PALAVRAS-CHAVE: vulnerabilidade social; imigrantes/refugiados; Covid-19.

\footnotetext{
1 Pontifícia Universidade Católica de Minas Gerais (PUC-Minas), Belo Horizonte - MG - Brasil. Doutora no Programa de Pós-graduação em Administração. Universidade Federal de Mato Grosso (UFMT), Cuiabá - MT Brasil. Professora adjunta. ORCID: https://orcid.org/0000-0002-5703-6165.kypl_pl@hotmail.com

2 Universidade Federal de Minas Gerais (UFMG), Belo Horizonte - MG - Brasil. Pós-Doutorado no Programa de Pós-graduação em Literatura de Línguas Portuguesa. Universidade do Estado de Mato Grosso (UNEMAT), Cárceres - MT - Brasil. Historiador e professor adjunto. ORCID: https://orcid.org/0000-0003-1118-4661. hralvess@ hotmail.com
} 


\title{
THE INTERFACES OF SOCIAL VULNERABILITY OF IMMIGRANTS AND REFUGEES IN FRONT OF COVID-19: MATO-GROSSENSE SCENARIO
}

\begin{abstract}
The objective of this study is to assess the impacts of the Covid-19 pandemic on the immigrant and refugee population in Mato Grosso. The situation of social vulnerability has been aggravated by the increase in social inequalities during the pandemic. Mato Grosso, where the fallacy of a "rich agricultural state" is not a reality for everyone, has seen a considerable increase in immigrants in the last decade, which, when trying to insert itself socially, faces the most varied challenges. The methodological paths are inscribed in the qualitative perspective; using the snowball method, data were collected from 30 immigrants and refugees, who underwent a content analysis with an interpretive bias - not limited to just the statements. The main results indicate that the pandemic intensified the situation of social vulnerability of immigrants and refugees in Mato Grosso, and that social vulnerability has different interfaces, such as: economic, health, legal, psychological, among others not explored in the study.
\end{abstract}

KEY-WORDS: social vulnerability; immigrants /refugees; Covid-19.

\section{Introdução}

O fenômeno da imigração acomete tanto aqueles que migram voluntariamente, ou seja, os imigrantes, como também aqueles que se veem por algum motivo obrigados a migrar, podendo ser chamados de refugiados. Ambos estão expostos a diferentes tipos de violação de direitos, a qual tem se agravado com a chegada da pandemia de Covid-19. O próprio fenômeno da migração já é, por si, algo bastante complexo. Além de elementos que influenciam nas relaçóes e dinâmicas sociais, tais como como fluxos, origem, destino, decorrência, periodicidade, dentre outros, acrescenta-se a pandemia da Covid-19, cujos efeitos não deixaram de atingir a populaçáo imigrante ${ }^{3}$ e refugiada do Brasil e de outros países e continentes.

A pandemia de Covid-19 anunciada pela Organização Mundial da Saúde OMS - ainda no início de 2020 atingiu todos os continentes, e expôs ao mundo, em maior ou menor grau, as fragilidades de cada país atingido. O modo de enfrentamento da pandemia passa, então, a expor mazelas sociais muitas vezes

\footnotetext{
3 Utilizar-se-á o termo imigrante neste artigo, uma vez que a pesquisa não se direcionou aos migrantes de modo geral e, sim, aos migrantes internacionais e refugiados.
} 
mascaradas ou simplesmente ignoradas por governantes. No Brasil, ela escancara as desigualdades sociais, enquanto ceifa a vida de milhares de brasileiros.

Ao contrário do que postulou o governo brasileiro, a pandemia de Covid-19 extrapolou as fronteiras dos grandes centros urbanos e passou a se interiorizar no país, fenômeno que também aconteceu com a imigração, tendo em vista o Programa do Governo Federal, que tem incentivado imigrantes a trabalharem em regiôes mais remotas. O que se vê, também, é a interiorização da Covid-19 nos locais mais longínquos do país, acometendo diferentes grupos sociais já em situação de vulnerabilidade, além dos imigrantes e refugiados que residem em Mato Grosso. Nesse sentido, o objetivo deste estudo visa avaliar os principais impactos da pandemia de Covid-19 sobre a população imigrante e refugiada no estado de Mato Grosso. Observando-se as diferentes faces da vulnerabilidade social atreladas à essa população, mostra-se oportuno chamar a atenção para o agravamento das desigualdades sociais e para o não desenvolvimento de políticas públicas capazes de possibilitar alternativas de emprego e renda para os indivíduos pertencentes a esses grupos sociais.

Mato Grosso, que não se configura como um estado altamente populoso, transmite uma imagem de "estado agrícola rico" que sugere à população em geral a ideia de que promoveria grandes oportunidades de trabalho e de enriquecimento, o que não se configura como uma realidade para todos, e sim como uma falácia. Porém, constata-se que houve um aumento considerável da população imigrante e refugiada na última década no estado. Ao tentar se inserir socialmente, esse grupo social se depara com as mais variadas dificuldades, intensificadas, hoje, com as questôes da pandemia.

A dificuldade de conseguir trabalho já vinha sendo realidade de muitos imigrantes em Mato Grosso, sobretudo daqueles que residem na capital do estado. Entretanto, essa realidade também passou a fazer parte da vida dos que buscaram outras cidades interioranas para se inserirem no mercado de trabalho. A maioria desses imigrantes e refugiados trabalha na prestação de serviços e na informalidade, e não são absorvidos diretamente pela indústria do agronegócio. Com a falta de emprego, imigrantes e refugiados ficaram mais vulneráveis, e passaram a depender de auxílio para se manterem, seja de alguma instituição referência que os acolhe, seja da ajuda emergencial do governo federal, ou ainda da solidariedade da população em geral.

Dentro deste contexto, este estudo se justifica, uma vez que a situação de vulnerabilidade social dos imigrantes e refugiados em Mato Grosso mostra-se acentuada neste momento de pandemia. Os pedidos de ajuda para compra de itens básicos de sobrevivência têm aumentado, segundo informaçóes da assis- 
tência social de alguns municípios e entidades religiosas que acompanham essa populaçáo. Na medida em que eles perderam seus postos de trabalho, passaram a ter dificuldade para honrar compromissos financeiros essenciais, tais como aluguel, conta de água, de energia, dependendo, assim, da solidariedade alheia para sobreviver. A necessidade de ajudar as famílias que permanecem em seus países de origem é também algo que angustia muito esses imigrantes.

Sendo assim, este artigo se estrutura na apresentação desta seção introdutória, seguida de uma breve contextualização teórica sobre a situação de vulnerabilidade social de grupos de imigrantes e refugiados, a fim de proporcionar uma visão panorâmica da situação desses grupos no estado de Mato Groso. Posteriormente, apresentar-se-á análise e discussão de dados coletados em campo, além de algumas reflexóes finais.

\section{Vulnerabilidade social intensificada na/pela pandemia}

A vulnerabilidade social se apresenta de várias formas diante de diferentes contextos sociais; com a pandemia do Covid-19, as interfaces da vulnerabilidade foram ganhando novos contornos, e os imigrantes e refugiados passaram a incorporar, com maior frequência, os já anteriormente populosos grupos marginalizados socialmente. A pandemia de Covid-19 trouxe à tona, mais uma vez, as desigualdades sociais e os rostos daqueles que estáo à margem da sociedade brasileira por não terem condiçóes, sobretudo financeiras, de se manterem ativos dentro da lógica capitalista de produção.

Em termos conceituais, a vulnerabilidade social diz respeito a carências sociais, econômicas, psicológicas ou físicas que colocam grupos ou indivíduos em maior risco, seja do bem-estar social ou da vida (TEIXEIRA, 2006). Inouye et al. (2010) comparam a vulnerabilidade social à uma síndrome multidimensional. Busso (2001) indica três fatores que definem a situação de vulnerabilidade social: i) a fragilidade ou desproteção frente às mudanças; ii) a debilidade interna para realizar mudanças necessárias a fim de aproveitar os recursos que estão ao seu alcance; iii) a insegurança que desmotiva açôes com o objetivo de lograr melhores condições de vida.

Pode-se perceber que embora haja conceitos diversos, eles coadunam no sentido de que a vulnerabilidade social está relacionada à capacidade que indivíduos ou grupos tem de controlar as forças que afetam seu bem-estar social e as oportunidades que aparecem em meio a este espaço (INOUYE et al., 2010; SANTOS, 2015). 
Dentre os diferentes sentidos que o uso do termo vulnerabilidade social abarca, o que mais se postula é a de situação de pobreza a que determinados indivíduos ou grupos estão expostos, apresentando-se em riscos pessoais, sociais ou ambientais (PRATI; COUTO; KOLLER, 2009). Estudos de outras áreas sondam essa vulnerabilidade social pela perspectiva da saúde (INOUYE et al., 2010), da educação (SILVA, S.; RAPOPORT, 2013), da psicologia (GAMA; CAMPOS; FERRER, 2014), dente outras.

A vulnerabilidade social, para além de categorias de camadas sociais, denuncia as injustiças e escancara as desigualdades de condiçôes de acesso a produtos e serviços sociais. Essa situaçáo se intensificou com a chegada da pandemia, agravando a situação de vulnerabilidade de pessoas que já estavam sujeitas a essas desigualdades, além de outras que estão sendo desprotegidas diante das mudanças postas pela atual crise sanitária e incapacidade de gestão pública eficiente (PORTO, 2020; PARISE; CARVALHO; PEREIRA, 2020).

A questáo da vulnerabilidade social em meio a pandemia ganha destaque, considerando o empobrecimento da população neste contexto, sobretudo aquelas já inseridas em situação de vulnerabilidade social (SILVA, I.; LUCENA FILHO, 2020; PORTO, 2020; MATHIS, 2020) e que agora ficam ainda mais suscetíveis a todo tipo de riscos.

Na reflexão de Porto (2020, p.01), "a crise atual faz parte de uma crise civilizatória mais ampla com múltiplas dimensóes - social, econômica, democrática, ambiental e sanitária -, e que a saúde pública/coletiva precisará se reinventar numa perspectiva emancipatória” Mathis (2020), ao fazer uma leitura da vulnerabilidade social no estado do Pará, chama atenção para o aumento de pessoas vivendo na extrema pobreza durante a pandemia. Silva Lucena e Filho (2020) atentam para o fato de as pessoas em situação de vulnerabilidade social estarem mais expostas às consequências na saúde mental agora e no momento pós pandemia.

A situação de vulnerabilidade social coloca desafios para a população imigrante e refugiada em tempos da pandemia, sinaliza a International Organization for Migrations (IOM, 2020). Outras entidades da sociedade civil como a Conectas Direitos Humanos chamam a atenção para a crescente situação de vulnerabilidade social dos imigrantes neste período, enfatizando também a redução dos atendimentos de serviços em diferentes áreas, seja nos agendamentos para atendimento junto a polícia federal, na emissão de documentos, dentre outros serviços que estão suspensos por conta da pandemia (BRASIL, 2020). Estudos recentes sobre os reflexos da pandemia afirmam que a crise sanitária expos a exploração da miséria e da precarização do trabalho que circundam a população 
migrante e outras minorias sociais (PARISE; CARVALHO; PEREIRA, 2020; PORTO, 2020).

Mattos (2020) afirma que os refugiados são uma categoria de imigrantes que estão ainda mais vulneráveis pela própria situação migratória, e que o Estado não deve restringir qualquer acesso desta população sob pena de discriminação. Outro aspecto jurídico que tem exposto as fragilidades dos imigrantes e refugiados diz respeito a situação migratória que muitos indivíduos vivenciam, como a fragilidade dos que aguardam a possibilidade de agendamento (suspensas no momento) para se apresentarem a polícia federal, e os solicitantes de refúgio que esperam o reconhecimento apenas com o protocolo de solicitação em mãos, documento muitas vezes não aceito por instituiçôes brasileiras, apesar de ser reconhecido pelos órgáos competentes.

Ainda dentro da perspectiva jurídica, Delfim (2020) atesta sobre as ameaças e retrocessos na legislação brasileira que resguardam direitos a imigrantes e refugiados, impostos pela Portaria Interministerial n. 340 de 30 de junho de 2020 (BRASIL, 2020b), que coloca restriçóes para a entrada de estrangeiros no país. Segundo Delfim, a portaria coloca restriçóes de entrada e discrimina refugiados e venezuelanos. Propóe a deportação sumária para aqueles que não se enquadram nos casos de permissáo de entrada previstos pela portaria e veta a entrada de venezuelanos, mesmo que tenham o visto de permanência, o que viola a própria Lei de Migração - 13.445/2017 (BRASIL, 2017). A portaria ainda desconsidera dinâmicas mundiais que não cessaram por conta da pandemia, e prevê a "inabilitação do pedido de refúgio", o que também fere os direitos dos refugiados já garantidos pela própria Lei de refúgio - Lei 9474/1997 ao negar o direito de solicitação do pedido de refúgio. A portaria também não faz menção àqueles que possuem visto humanitário (DELFIM, 2020).

A proposta deste artigo ocupa-se, então, em entender a situação de vulnerabilidade social como chave de leitura conceitual para que se consiga compreendê-la dentro do universo das migraçôes.

\section{Imigrantes e refugiados em Mato Grosso}

As motivações para a migração são diversas e acompanham a humanidade desde seus primórdios, no entanto, o fenômeno da imigração contemporânea é motivado, significativamente, por razóes econômicas (PATARRA; FERNANDES, 2011; PARISE, 2018). Essa motivação tem implicaçóes diretas no mercado de trabalho em que se inserem imigrantes e refugiados. Eles procuram se inserir neste contexto, seja pelas vias do trabalho formal ou informal. Um 
mercado de trabalho atraente, pode configurar-se um incentivo poderoso para os estrangeiros que migram em busca de melhores condiçóes de vida, embora o Brasil não tenha tradição de possuir um mercado de trabalho aquecido (oferta de trabalho em alta), nos anos de 2012 até 2015 o país passou a chamar a atenção de muitos imigrantes por apresentar melhores oportunidades de emprego e aumento das vagas de trabalho, fomentadas em grande parte pela construção civil (PATARRA; FERNANDES, 2011; STEFANELLI; BASTOS, 2016).

Estudos que mapeiam a geopolítica das migraçóes como os de Baeninger (2016) já apresentava indícios da capilarização das migraçôes contemporâneas no Brasil. Uma das coordenadoras do estudo aponta que "a rota das migraçóes internacionais no Brasil passa pelas fronteiras, segue para as metrópoles, principalmente das regióes Sul e Sudeste do país, e se espalha para outros estados" (BAENINGER, 2018). Matos (2013) discute a importância dos imigrantes nos processos de desconcentração demográfica contemporânea, e pondera que os imigrantes figuram positivamente nos segmentos de mercado de trabalho de microrregióes mais afastadas dos grandes centros urbanos brasileiros (referindo-se a São Paulo e Rio de Janeiro), o que explicaria o crescimento da presença de imigrantes em estados como Mato Grosso, nos anos referenciados.

Tannock (2015) e Riaño e Piguet (2016) sinalizam que os imigrantes e refugiados se inserem nas novas demandas do mercado de trabalho contemporâneo, pois se faz evidente a necessidade de prospectar os impactos e efeitos que as migraçóes trazem às relaçóes de trabalho, sobretudo em economias emergentes, como a brasileira. Os imigrantes internacionais passaram então a incorporar as agendas de discussóes das empresas na medida em que essa mão de obra passa a ser uma alternativa para a cadeia produtiva, considerando-se a flexibilização das leis trabalhistas, a Reforma Trabalhista de 2017 e modernização das relaçóes de trabalho, que passaram a pautar novas dinâmicas entre os atores sociais dessas interaçóes (HOPKINS; DAWSON; VELIZIOTIS, 2016).

A imigração internacional também coloca questóes para a dinâmica do sistema produtivo brasileiro atrelada à disposição espacial em que esse contingente vem se inserindo atualmente. Um estudo recente de Baeninger, Demétrio e Domeniconi (2020) pontua que a chegada dos imigrantes internacionais altera a dinâmica de reprodução da força de trabalho, bem como para o modo de relação com o espaço urbano. Os processos de reestruturação urbana e produtiva empurram os menos qualificados para longe do centro metropolitano, mas também há um movimento que concentra nos novos centros produtivos a presença desta força de trabalho qualificada, demarcando os diferentes espaços de migração. Pode-se pensar, deste modo, o fato de regióes como Mato Grosso passarem a 
incorporar o destino de alguns imigrantes e refugiados, além de estratégias governamentais de interiorização dessa população a fim de que sejam mais facilmente inseridos na sociedade.

Essas e outras dinâmicas pautavam as discussôes no campo dos impactos sobre a economia e a relação do trabalho e sua interface com o fenômeno migratório no Brasil e no mundo; porém, com a chegada e rápida expansão da pandemia de coronavírus, o fenômeno da mobilidade humana fica ainda mais tencionado. O anúncio da pandemia de SARS-CoV-2 (Covid-19) proferido pela World Health Organization (WHO, 2020), ainda no início de 2020, fez colocar uma atenção ainda maior para os já conhecidos desafios da humanidade; sob essa perspectiva pode-se entender as diferentes preocupaçóes e discussóes levantadas por organismos como United Nations High Commissioner for Refugees (UNHCR, 2020) e também a International Organization for Migrations (IOM, 2020).

Estudos ainda genéricos acerca dos primeiros impactos da pandemia sobre a população imigrante e refugiada pontuam respostas que os países vêm destinando ou não para esses grupos sociais. Exemplos destes tipos de abordagens pautam a necessidade de amparo dessa população diante da pandemia de Covid-19, independentemente do status migratório (KLUGE et al., 2020; ORCUTT et al., 2020).

A respeito do contexto brasileiro da pandemia de Covid-19 relacionado aos imigrantes, um estudo recente apresenta, por meio de uma pesquisa fenomenológica, alguns dos impactos causados pela pandemia que tem afetado a população refugiada, considerando as respostas dadas pelo governo federal frente a pandemia. Os resultados apontam que os refugiados são afetados principalmente pelo fechamento das fronteiras e tem seus direitos violados no acesso à documentação, à saúde e à assistência social (MARTUCELLI, 2020).

A quantidade de imigrantes e refugiados que adentraram em território brasileiro nas últimas décadas tem se intensificado; no entanto, devido à pandemia de Covid-19 e com o fechamento de fronteiras, a entrada de novos imigrantes caiu drasticamente. Estimativas da Organização Internacional da Migraçóes computam que em 2019 havia mais de 270 milhóes de migrantes internacionais no mundo (IOM, 2019). A agência da ONU para refugiados soma 79,5 milhóes de pessoas forçadas a deslocar-se de seus locais de origem; este cenário produziu cerca de 26 milhóes de refugiados (UNHCR, 2020). No Brasil, o número de imigrantes e refugiados não é significativamente expressivo, pois não chega a representar $1 \%$ por cento da população brasileira; cifras da (IOM, 2020) apontam que há cerca de 800 mil imigrantes em território nacional, o que representa 
0,4\% da população, com destaque para os dois fluxos mais presentes na última década, haitianos e venezuelanos.

Em relação aos refugiados, estimativas mais recentes do Comitê Nacional para Refugiados - CONARE, órgão vinculado ao Ministério da Justiça e Segurança Pública, afirmam que há mais de 219 mil solicitantes de refúgio no Brasil, e cerca de 130 mil são de pedidos de refúgio de venezuelanos. Deste total, 43 mil pessoas já foram reconhecidas como refugiados (UNHCR, 2020). Segundo informaçóes veiculadas pelo órgão, cerca de $80 \%$ dos 43 mil pedidos já reconhecidos de refúgio foram concedidos aos venezuelanos, havendo, nesse sentido, aproximadamente 260 mil deles que residem no Brasil (BRASIL, 2019).

Entre 2000 e 2015 Mato Grosso registrou a chegada de 5087 imigrantes internacionais, conforme dados do Atlas Temático de Observação das Migraçóes (BAENINGER et al., 2018). Só em 2015 mais de 117 mil imigrantes entraram no país (BRASIL, 2018); porém, o estado de Mato Grosso não se mostrava como destino final de muitos desses imigrantes. A Polícia Federal tem registros ativos de mais de 12 mil estrangeiros vivendo atualmente em Mato Grosso (BRASIL, 2019). O estado registrou um aumento expressivo desta população na última década, sobretudo de haitianos, entre os anos de 2012 e 2015 e, mais recentemente, de venezuelanos, conforme estudo de Pellizari (2019).

Mato Grosso tem recebido como fluxo mais frequente os venezuelanos vindos ao estado motivados pelo Programa de Interiorização do Governo Federal; a Polícia Federal computa que vivem atualmente no estado mato-grossense mais de 1400 venezuelanos (BRASIL, 2019). A maioria destes imigrantes foram acolhidos em um primeiro momento no Centro de Pastoral para Migrantes de Cuiabá - CPM-Cuiabá, e a entidade estima que até o momento há mais de 3000 venezuelanos vivendo em Mato Grosso. Atualmente o fluxo de imigrantes e refugiados no estado quase zerou por causa da pandemia e do fechamento de fronteiras terrestres (CPM-Cuiabá, 2020). Embora não se tenham dados sobre migrantes não documentados no estado, a coordenação da referida casa de acolhida não tem registrado entrada de novos imigrantes na instituição e tampouco recebido demandas destes recém-chegados entre os meses de abril e setembro de 2020; a organização atende a todos sem distinção.

A maioria dos imigrantes e refugiados que residem em Mato Grosso trabalha na prestação de serviços e na informalidade, não sendo absorvidos diretamente pela indústria do agronegócio, apesar da presença desses imigrantes ser maior nas cidades fomentadas por esta atividade econômica (PELLIZARI; ROQUE-FARIA, 2017). Com a falta de emprego intensificada pela pandemia, 
imigrantes e refugiados ficaram mais vulneráveis, e passaram a depender de auxílio para se manter.

O Centro de Pastoral para Migrantes de Cuiabá é uma instituição de referência na acolhida desta população no estado, e muitas vezes torna-se a única alternativa aos imigrantes e refugiados que chegam à capital. Para aqueles que se deslocaram a outras cidades do interior, a rede de contatos dos imigrantes é a fonte mais segura de auxílio, salvaguardada pela solidariedade da população em geral ou de algumas instituiçóes religiosas que desenvolvem projetos junto a essa população em alguns municípios do interior do estado (PELLIZARI, 2019).

Estudos sobre imigrantes e refugiados que circundam o contexto mato-grossense abordam temáticas distintas, tais como: a saúde por Alves et al. (2019), Leão et al. (2018); gênero e violência contra a mulher imigrante por Topas, Neves e Nogueira (2013); imigração e redes sociais por Guimarães e Alonso (2017); a inserção laboral de imigrantes por Pellizari e Mazaro (2018); as relações de trabalho e os imigrantes e refugiados por Pellizari (2019); a interface entre saúde e trabalho dos imigrantes por Leão el al. (2017) são alguns dos muitos trabalhos já publicados; porém, estudos direcionados especificamente à pandemia de Covid-19 representam uma lacuna a ser explorada.

\section{Caminhos metodológicos}

Esta pesquisa inscreve-se dentro de uma perspectiva qualitativa, uma vez que se prevê fazer uma análise diante do fenômeno que se observa. Com este enfoque é possível que se tenha um quadro mais amplo, uma visão holística, com detalhes de informaçóes (MARIZ et al. 2005). Essa abordagem permite ao pesquisador não apenas inferir reflexóes sobre o que observar, mas também tentar compreender tal fenômeno em seu contexto social e as interfaces que implicam na vida dos sujeitos. Haguette (2003, p.63) afirma que a pesquisa qualitativa "fornece uma compreensão profunda de certos fenômenos sociais apoiados no pressuposto da maior relevância do aspecto subjetivo da ação social face à configuração das estruturas societais"

Os passos metodológicos compreendem a abordagem de pesquisa, o olhar que se dá à pesquisa, as técnicas empregadas para a coleta de dados e os mecanismos de análise e interpretação dos dados. A operacionalização deste trabalho foi construída com mecanismos propícios para uma pesquisa mais ampla que culminou em uma tese doutoral; assim, alguns dos participantes que compuseram este estudo foram re-abordados pela pesquisadora e auxiliaram na coleta de dados, bem como possibilitaram uma metodologia de alcance dos demais 
imigrantes e refugiados, mesmo em meio ao contexto de pandemia, período em que um estudo empírico presencial não seria tido como muito apropriado.

Munindo-se de informaçóes e com alguns contatos realizados anteriormente, foi possível acessar os 30 participantes desta pesquisa por meio da metodologia, denominada no Brasil, de bola de neve (GRAY et al., 2007). Esta metodologia pode ser construída ao longo do processo de pesquisa, e consiste na indicação dos participantes por outros previamente acessados, no caso, os imigrantes e refugiados que participaram da pesquisa doutoral e que para este momento representaram as sementes da amostra, termo que se utiliza para indicar as entrevistas iniciais ou contatos iniciais (FAUGIER; SARGEANT, 1997).

A metodologia adotada mostrou-se oportuna por duas razóes. Primeiro deve-se observar que, devido ao contexto de pandemia, não seria adequado transitar presencialmente em busca desses sujeitos; além disso, imigrantes e refugiados se mostram receosos ao falar de suas condiçóes de vida. Neste sentido, a metodologia foi produtiva, uma vez que a pesquisadora foi previamente indicada/apresentada por alguém familiar ao entrevistado, ainda que via telefone. Salganik e Heckathorn (2004) afirmam que este método de coleta de dados é indicado quando não se conhece os participantes, quando delimitá-los é oneroso, ou ainda, quando se leva um tempo de que não se dispóe.

As entrevistas contemplaram ao todo 30 imigrantes e refugiados que vivem no estado de Mato Grosso em diferentes cidades. Para as 5 entrevistas sementes solicitou-se a indicação de três amigos (refugiado ou imigrante) que pudessem participar da pesquisa; o único critério residiria no fato de que eles deveriam viver em Mato Grosso. Houve três rodadas de indicações: a) na primeira foram validadas (aceitas pelos participantes) 06 entrevistas; b) na segunda foram validadas 08 entrevistas; c) na terceira rodada foram validadas mais 11 entrevistas, perfazendo um total de 30 entrevistados ( 5 sementes $+06+08+11=30$ ).

As entrevistas foram realizadas via telefone, individualmente, de modo objetivo e com base em um roteiro semiestruturado (GASKELL; BAUER, 2002). Buscou-se identificar, junto aos participantes, como estavam enfrentando a pandemia, suas principais dificuldades e situação laboral no momento da pesquisa. O levantamento de dados aconteceu no período de 15 de maio a 30 de junho de 2020. Houve a necessidade de se pontuar, antes de cada entrevista, que os dados serviriam apenas para uma pesquisa acadêmica, e que as informaçôes repassadas não seriam fornecidas a ninguém mais, além de se mencionar que não era uma consulta de entidade governamental a fim de conceder ou não o auxílio emergencial. Esse receio dos imigrantes e refugiados também ajudou a compreender o motivo das desistências de alguns deles de participarem da 
pesquisa. Todas as entrevistas foram gravadas e transcritas visando a reprodução fiel das narrativas, além de manter as diferenças linguísticas e elementos da oralidade (GASKELL; BAUER, 2002). O roteiro de pesquisa foi adequado após as entrevistas com as 5 sementes, de modo a torná-lo mais objetivo e com linguagem mais apropriada. Um breve perfil dos entrevistados pode ser ilustrado no quadro a seguir:

Quadro 01 - Breve perfil dos imigrantes e refugiados entrevistados em Mato Grosso

\begin{tabular}{|c|c|c|c|c|c|c|c|}
\hline Código & Idade & Sexo & Nacionalidade & $\begin{array}{c}\text { Vive com } \\
\text { Filhos/ } \\
\text { Quantos }\end{array}$ & $\begin{array}{l}\text { Situaçáo laboral/ } \\
\text { Formal ou Informal }\end{array}$ & $\begin{array}{c}\text { Precisou de } \\
\text { ajuda na } \\
\text { pandemia }\end{array}$ & $\begin{array}{l}\text { Local de } \\
\text { residência }\end{array}$ \\
\hline IM001 & 28 & M & Haitiano & $\operatorname{Sim} / 01$ & Empregado/formal & Não & Cuiabá-MT \\
\hline IM002 & 30 & $\mathrm{~F}$ & Venezuelana & $\mathrm{Sim} / 02$ & Desempregada & Sim & Cuiabá-MT \\
\hline IM003 & 38 & M & Angolano & Náo & Empregado/ formal & Năo & Cuiabá-MT \\
\hline IM004 & 22 & $\mathrm{~F}$ & Venezuelana & $\operatorname{Sim} / 02$ & Desempregada & Sim & Cuiabá-MT \\
\hline IM005 & 50 & M & Congolês & Não & Desempregado & Sim & Cuiabá-MT \\
\hline IM006 & 45 & $\mathrm{~F}$ & Cubana & $\operatorname{Sim} / 01$ & Empreendedora/informal & Sim & Cuiabá-MT \\
\hline IM007 & 31 & M & Senegalês & Não & Empreendedor/informal & Sim & Cuiabá-MT \\
\hline IM008 & 29 & M & Venezuelano & $\mathrm{Sim} / 04$ & Empregado/ informal & Sim & Várzea Grande-MT \\
\hline IM009 & 30 & M & Haitiano & Năo & Desempregado & Sim & Várzea Grande-MT \\
\hline IM010 & 37 & M & Haitiano & $\mathrm{Sim} / 03$ & Desempregado & Sim & Várzea Grande-MT \\
\hline IM011 & 26 & $\mathrm{~F}$ & Venezuelana & $\operatorname{Sim} / 02$ & Empregado/informal & Sim & Cuiabá-MT \\
\hline IM012 & 23 & M & Haitiano & Não & Desempregado & Sim & Cuiabá-MT \\
\hline IM013 & 38 & M & Venezuelano & $\operatorname{Sim} / 02$ & Empregado/informal & Sim & Cuiabá-MT \\
\hline IM014 & 34 & $\mathrm{~F}$ & Haitiana & $\operatorname{Sim} / 01$ & Empreendedor/informal & Sim & Sinop- MT \\
\hline IM015 & 26 & $\mathrm{~F}$ & Haitiana & Não & Desempregada & Sim & Sinop-MT \\
\hline IM016 & 30 & M & Venezuelano & $\mathrm{Sim} / 02$ & Empregado/informal & Não & Sinop-MT \\
\hline IM017 & 43 & M & Venezuelano & Náo & Empregado/informal & Năo & Sinop-MT \\
\hline IM018 & 37 & M & Haitiano & $\operatorname{Sim} / 01$ & Empregado/formal & Não & Sinop-MT \\
\hline IM019 & 30 & $\mathrm{~F}$ & Venezuelana & Não & Desempregada & Sim & Rondonópolis-MT \\
\hline IM020 & 28 & M & Boliviano & $\operatorname{Sim} / 02$ & Empregado/informal & Sim & Rondonópolis-MT \\
\hline IM021 & 23 & $\mathrm{~F}$ & Haitiana & Náo & Desempregada & Sim & Rondonópolis-MT \\
\hline IM022 & 21 & F & Venezuelana & Não & Empregado/informal & Não & Lucas do Rio Verde-MT \\
\hline IM023 & 33 & M & Haitiano & Náo & Desempregado & Sim & Lucas do Rio Verde-MT \\
\hline
\end{tabular}




\begin{tabular}{|l|c|c|l|c|c|c|l|}
\hline Código & Idade & Sexo & Nacionalidade & $\begin{array}{c}\text { Vive com } \\
\text { Filhos/ } \\
\text { Quantos }\end{array}$ & $\begin{array}{r}\text { Situaçáo laboral/ } \\
\text { Formal ou Informal }\end{array}$ & $\begin{array}{c}\text { Precisou de } \\
\text { ajuda na } \\
\text { pandemia }\end{array}$ & $\begin{array}{c}\text { Local de } \\
\text { residência }\end{array}$ \\
\hline IM024 & 40 & $\mathrm{~F}$ & Haitiana & Sim/03 & Desempregada & Sim & Lucas do Rio Verde-MT \\
\hline IM025 & 22 & $\mathrm{M}$ & Haitiano & Não & Empregado/formal & Não & Chapada Guimarães-MT \\
\hline IM026 & 30 & $\mathrm{M}$ & Boliviano & Não & Empregado/formal & Não & Nova Mutum-MT \\
\hline IM027 & 40 & $\mathrm{M}$ & Venezuelano & Sim /01 & Desempregado & Sim & Alta Floresta-MT \\
\hline IM028 & 43 & $\mathrm{M}$ & Haitiano & Sim/01 & Empreendedor/informal & Não & Sorriso-MT \\
\hline IM029 & 18 & $\mathrm{M}$ & Venezuelano & Não & Desempregado & Sim & Sorriso-MT \\
\hline IM030 & 28 & $\mathrm{~F}$ & Venezuelana & Sim/01 & Empregada/informal & Sim & Sorriso-MT \\
\hline
\end{tabular}

Fonte: Elaborado com dados da pesquisa.

Ainda referindo-se aos passos metodológicos, faz-se importante observar que se adotou como estratégia de análise de dados a análise de conteúdo tal qual proposta por Vergara (2005), em que possibilita a sistematização dos achados de pesquisa em quadros que contemplam os recortes das narrativas agrupados por elementos temáticos. Essa sistematização favorece a inter-relação das narrativas e ajuda a compreendê-las, considerando o espaço e tempo em que foram construídas por seus sujeitos, o que possibilita releituras e análises de cunho crítico e reflexivo.

Para facilitar a análise dos dados, os recortes das entrevistas foram identificados de acordo com os códigos de IM001 a IM030, conforme Quadro 01 acima apresentado.

\section{Análise dos dados: as interfaces da vulnerabilidade social dos imigrantes e refugiados em MT}

A análise dos dados coletados a campo buscou, por meio de sucessivas leituras, a fim de se compreender os contextos em que se inseriam, estabelecer uma relação entre os elementos mais recorrentes das entrevistas. Após esta etapa, foram selecionados os recortes que compuseram a análise. As entrevistas que continham elementos narrativos que se assemelhavam foram agrupadas conforme os quadros abaixo, seguindo sugestóes de sistematização pontuadas por Vergara (2005). Deste modo, a análise realizada não será centrada nos pormenores de cada recorte dos entrevistados, mas sim no ponto principal de interseção que une cada grupo de narrativas. 
Vale pontuar que os conceitos apresentados sobre vulnerabilidade social ponderam diferentes variáveis, e que nem todas elas foram exploradas nesta análise, considerando-se a limitação de tempo e proposta. Ressalta-se ainda que os imigrantes e refugiados não são por si só vulneráveis, pois na verdade a vulnerabilidade social é uma situação em que determinado indivíduo se encontra e que pode ser momentânea, não sendo inerente a nenhum ser humano pelo fato dele apenas existir. Este estudo busca justamente chamar a atenção para esta situação de vulnerabilidade social a que os imigrantes estão expostos.

O que se apresenta a seguir é uma análise interpretativista das narrativas e sua relação com as variáveis que moldam a situação de vulnerabilidade social dos participantes da pesquisa. Entende-se que os recortes apresentados possuem elementos de narrativas que devem ser pensados, e náo desconexos dentro do contexto social de exclusão e desigualdades. Assim, chama-se a atenção não apenas para o que se é dito, mas, e sobretudo, por quem é dito e de que lugar se produz essa narrativa.

Entrevistou-se para este estudo 30 participantes, todos residentes atualmente no estado de Mato Grosso e presentes em nove (09) municípios, com destaque para quatro (04) das maiores cidades mato-grossenses, que são Cuiabá, Várzea Grande, Rondonópolis e Sinop. Os entrevistados são de sete (07) nacionalidades, com maior destaque para as mais frequentes, ou seja, a venezuelana e haitiana, o que se explica devido a presença mais expressiva destas nacionalidades nas estatísticas da população imigrante em Mato Grosso. Do total de entrevistados, 19 declararam-se solicitantes de refúgio e/ou refugiados, 11 são imigrantes e 63\% destes são homens. Neste contexto de pandemia, apenas 05 entrevistados afirmaram ter emprego formal e estarem trabalhando, ao passo que 13 disseram estar sem trabalho algum, 04 são pequenos empreendedores informais e os demais trabalham na informalidade. De todos os que participaram da pesquisa, apenas 07 imigrantes disseram não ter precisado de algum tipo de ajuda desde o início da pandemia, sinalizando que $90 \%$ dos imigrantes e refugiados entrevistados precisaram de auxílio para manter suas necessidades mais básicas de alimentação, moradia, saúde e assistência social (para o auxílio emergencial conseguir algum tipo de documentação).

\section{A interface da vulnerabilidade econômica}

Discutiu-se, em nível conceitual, que a vulnerabilidade social se apresenta de diferentes formas; no entanto, considerou-se alguns critérios como parâmetros a fim de se possibilitar uma análise. Não raro, o elemento econômico figura 
como uma das variáveis observadas quando o quesito é categorização social. Dentro da lógica capitalista em que se vive, o fator financeiro pode representar muito mais do que ter ou não um montante em uma conta bancária, mas condiçôes dignas de sobrevivência em sociedade (PORTO, 2020).

Ainda pela lógica do capital, o trabalho configura-se como elemento que possibilita essa forma de obter recurso financeiro, de modo que há uma relação de compra/venda entre a força de trabalho e dinheiro. Desta forma, os imigrantes e refugiados buscam no trabalho uma forma de inserção social e meio de subsistência.

Os recortes a seguir trazem como elemento principal o trabalho e, mais explicitamente, as situaçóes de perdas desses empregos pelos imigrantes e refugiados em Mato Grosso diante do contexto da pandemia.

Quadro 2 - Recortes sobre aspectos laborais

\begin{tabular}{|c|c|}
\hline IM00 & $\begin{array}{l}\text { tinha emprego, estaba a trabajar.. minha patroa era buena, pero me mandou } \\
\text { bora quando tudo isso comezó, eu fiquei sem trabajo.. tengo família, meus dos } \\
\text { no dependem de mi. }\end{array}$ \\
\hline IM003 & $\begin{array}{l}\text { tenho trabalho... o restaurante continua na Covid, mas meu chefe corto salário, } \\
\text { s eu ainda tenho trabalho. A genti não da pra reclama! }\end{array}$ \\
\hline IM014 & $\begin{array}{l}\text { trabay de vendi na rua, mas a polícia di Brasil não deixa mais eu trabalhar, e eu } \\
\text { ı migrante não posso ser plesa. }\end{array}$ \\
\hline IM004 & $\begin{array}{l}\text { Perdi meu emprego porque mi jefe no deixa llevar mi hijo no trabajo, trabalho, } \\
\text {...mi hijo no tiene escola pra él. .... eu precisava do trabajo, pero não podia deixar } \\
\text { mi hijo solo a casa. }\end{array}$ \\
\hline IM007 & ho eul vendia na rua mas \\
\hline IM023 & era galçon, mas o restaur \\
\hline IM013 & $\begin{array}{l}\text { Estaba la pastoral, pero despues que el dinero do dinero del gobieno a casa cerró, } \\
\text { não hay trabajo e o dinero no es suficiente para comprar comida e pagar alquiler. }\end{array}$ \\
\hline IM0 & $\begin{array}{l}\text { u fazia diária, daí veio a pandemia e não tem mais trabalho. Estou a pensar em } \\
\text { ltar. }\end{array}$ \\
\hline
\end{tabular}

Fonte: Elaborado pela autora, com dados da pesquisa.

O emprego representa para os imigrantes e refugiados bem mais do que condiçóes de manter a vida em sociedade, mas também a chance de uma mudança de vida, seja dos que migraram ou daqueles que permaneceram e dependem dos recursos enviados pelos imigrantes, ou seja, as chamadas remessas (PARISE, 2018). 
Observa-se que a pandemia está presente como elemento propulsor do desemprego ou da impossibilidade em buscar uma forma de trabalho entre a população migrante. A escassez de trabalho já se fazia presente antes mesmo da pandemia, e a atual conjuntura só fez agravar a situação (PELLIZARI; ROQUEFARIA, 2017; PELLIZARI, 2019).

Neste sentido, pode-se observar não apenas a importância do trabalho para os entrevistados, mas também a preocupação com a falta dele. Diante das constataçóes do desemprego e limitaçóes no acesso à renda, percebe-se a face mais comum da vulnerabilidade social, sua interface econômica, o que expóe essa populaçáo às margens da sociedade, na medida em que demanda de ajuda para conseguir garantir sustento e moradia, ou seja, para as necessidades mais básicas de sobrevivência (PARISE; CARVALHO; PEREIRA, 2020; PORTO, 2020).

\section{A interface da vulnerabilidade sanitária}

A pandemia de Covid-19 atingiu a todos sem distinção; contudo, os efeitos que ela vem causando não se configuram nos mesmos moldes para os diferentes sujeitos. Muitos imigrantes e refugiados se defrontaram com essa situaçáo no meio de seus processos migratórios quando ainda não conseguiram se estruturar minimamente em termos de moradia e emprego (MATTOS, 2020).

Nos recortes a seguir, percebe-se que as situaçóes de habitação relatadas não apresentam as condiçôes de estrutura física das residências, mas demonstram a alta densidade familiar das habitaçôes. Essa situação impacta diretamente nas chances de proteção contra o Covid-19, já que, dadas as condiçôes habitacionais desta população, o isolamento social e distanciamento mostra-se impraticável (SILVA, I.; LUCENA FILHO, 2020; PARISE; CARVALHO; PEREIRA, 2020); sendo assim, os imigrantes e refugiados se veem mais propensos e expostos a doença.

Em Mato Grosso não há conglomerados populacionais com disposiçóes visualizadas nas favelas; no entanto, a população imigrante e refugiada vive, em sua maioria, em bairros muito humildes, compartilhando moradias urbanas bastante limitadas em termos de infraestrutura (LEÃO et al., 2018; PELLIZARI, 2019). Essas condiçôes de moradia estão diretamente relacionadas aos valores expressivos dos aluguéis praticados na região metropolitana de Cuiabá. 
Quadro 3 - Recortes sobre aspectos habitacionais e de saúde

\begin{tabular}{|c|l|}
\hline IM016 & $\begin{array}{l}\text { Na minha casa mora bastante gente, uma ocho personas, yo, mi filhos, minha } \\
\text { esposa, uma prima e o namorado dela e um casa. de amigos que não tinha onde } \\
\text { morar..... a gente ganha comida, e o dinero del goberno deu pra comprar comida, } \\
\text { peroó falta água meu bairro. }\end{array}$ \\
\hline IM029 & $\begin{array}{l}\text { Vivimos en una casa muy pequeña, en realidad tiene una gran sala, una cocina y } \\
\text { un baño, vivimos allí en tres personas y dos niños. }\end{array}$ \\
\hline IM021 & $\begin{array}{l}\text { Eu moro com meus amigo e meus amigos divide o aluguel do quarto, polque o alu- } \\
\text { guel é caro e a genti náo tem travail agora. Lá tem muitos haitianos, que vivem lá. }\end{array}$ \\
\hline IM005 & $\begin{array}{l}\text { Eu mora na casa do migrante com oltros.. je pense } 30 \text { personnes, mas depois do } \\
\text { dinheiro do governo la maison fermé, não tem travail e o dinheiro não compra } \\
\text { comida e loyer. }\end{array}$ \\
\hline IM018 & $\begin{array}{l}\text { Lá no meu kitineti tem cinco pessoa que mola comigo, é apertado si, a genti não } \\
\text { tem muito espaço..... a genti tem só a água que vem pela rua, mas tem dia que não } \\
\text { vem nada e a genti não tem reservatório di água. }\end{array}$ \\
\hline IM026 & $\begin{array}{l}\text { Meu chefe de obra ficou doente de covid, ele mandou a gente fica em casa, mas daí } \\
\text { eu não ganhei as comissáo..... depois voltou todo mundo...ehh só podia trabalha } \\
\text { de máscara.... nós ganhou mascara... aquelas de lava. }\end{array}$ \\
\hline
\end{tabular}

Fonte: Elaborado pela autora, com dados da pesquisa.

A fim de tornar o aluguel mais acessível, os imigrantes se reúnem em grupos e locam imóveis conjuntamente, com compatriotas ou não. Há relatos de que essa dinâmica também facilita a troca de cuidados pelas mães imigrantes, que muitas vezes náo conseguem creche no período integral e revezam os cuidados dos filhos com outras compatriotas.

É realidade frequente em alguns bairros da região metropolitana e no município de Várzea Grande a falta de água e saneamento básico, o que se torna um problema ainda maior para manter as recomendaçôes dos órgãos de saúde no cuidado com a higiene pessoal (WHO, 2020). Observa-se, ainda, que os imigrantes e refugiados se veem obrigados a aceitar essas condiçóes de moradia em que não conseguem cumprir o isolamento social, e que, por vezes, as condiçóes sanitárias não são adequadas, já que não conseguem pagar pelo aluguel de locais mais salubres para habitarem; dessa forma, políticas públicas de moradia para essa população são desconhecidas no estado.

\section{A interface da vulnerabilidade Jurídica}

Além da falta de emprego que oportuniza a renda e pode garantir melhores condiçóes de moradia, dentre outras benesses, os imigrantes e refugiados enfren- 
tam as sançóes jurídicas durante a pandemia, sendo afetados pela suspensão de alguns serviços de órgáos públicos, como a emissáo de documentação junto a Polícia Federal e demais pontuados por Delfim (2020).

Quadro 4 - Recortes sobre aspectos migratórios e legislativos

\begin{tabular}{|c|l|}
\hline IM027 & Mia hija ficou doente.... a UPA não atendi, porque no tenia documento brasilero. \\
\hline IM023 & $\begin{array}{l}\text { O dinhelo do governo eu não recebi ainda e eles falou porque eu tinha travay, mas } \\
\text { eu não tem travay, e eu esto passando necessidadi. }\end{array}$ \\
\hline IM024 & A moça da Caixa disse que meu CPF está errado, por isso eu não recebi o dinheiro. \\
\hline IM011 & $\begin{array}{l}\text { quiero trazer mi esposo de Venezuela, mas a fronteira está cerrada, él não pode } \\
\text { vim agora. }\end{array}$ \\
\hline IM022 & $\begin{array}{l}\text { Antes da Covid eu consegui mandar dinheiro pra meu hermano vir aqui no Brasil, } \\
\text { pero la fronteira no se cruza agora. }\end{array}$ \\
\hline
\end{tabular}

Fonte: Elaborado pela autora, com dados da pesquisa.

A interface da vulnerabilidade jurídica retrata a violação de direitos legais e garantidos por legislação específica, além de decisóes político-administrativas arbitrárias que atentam contra os imigrantes e refugiados, acentuando a fragilidade da condição ou situação migratória (MARTUCELII, 2020). Percebe-se os avanços e retrocessos jurídicos nas narrativas acima, na medida em que os entrevistados narram situaçóes cotidianas em que sofrem com os impactos, como o fechamento de fronteiras que atinge principalmente a população imigrante venezuelana que já reside no Brasil.

A Portaria interministerial N. 340 é um mecanismo legislativo que, além de discriminar alguns imigrantes, tem dificultado a vida dessas pessoas, sobretudo aquelas que já tinham permissão de residência no país. Com o fechamento de fronteiras, a entrada e trânsito de imigrantes praticamente sessou, já que a referida Portaria prevê pouquíssimos casos de exceção, sendo a reunificação familiar uma delas; mas no caso dos venezuelanos, esse direito está sendo negado pelo próprio artifício da lei (DELFIM, 2020). Outro ponto que tem causado discussóes entre os especialistas em migração internacional e de direitos humanos tem questionado a permanência do fechamento das fronteiras terrestres com o avançar da pandemia, contraposta à liberação de imigrantes por vias aéreas para acesso ao território brasileiro no mesmo período. Deste modo, paira no ar a ideia de que há uma pré-seleção por parte do Estado sobre os imigrantes que podem adentrar no Brasil neste momento de turbulência mundial. 
A dificuldade dos imigrantes e refugiados conseguirem os documentos de regularização migratória também acentua sua situação de vulnerabilidade social, pois limita o acesso a outros serviços, tais como: o acesso a saúde, a assistência social, ao auxílio emergencial, dentre outros. Entretanto, ter o documento em mãos não é garantia de receber o serviço, já que ainda há desconhecimento por muitos servidores públicos e privados sobre a documentação legal de imigrantes e refugiados que vigora no Brasil. A dificuldade no reconhecimento dos documentos provisórios, a exemplo do protocolo de refúgio, limita o acesso às unidades de saúde, aos bancos públicos ou privados, na busca por trabalho, no ato da contratação do imigrante; estes casos foram relatados em muitas narrativas; alguns foram resolvidos com a chancela de entidades que acolhem e trabalham com imigrantes, pois eles acabam por intervir junto ao órgão desinformado. Em outros casos, os imigrantes simplesmente não conseguem acessar o serviço/ oportunidade.

\section{A interface da vulnerabilidade psicológica marcada pelos medos e angústia}

Outro elemento bastante recorrente nas entrevistas está relacionado aos efeitos psicológicos que a pandemia tem causado em todos os indivíduos, não diferenciando os imigrantes e refugiados. A pressão que o próprio movimento migratório impóe aos imigrantes e refugiados direciona-os a uma situação delicada pois, somada a todas as incertezas e ameaças da Covid-19, acarreta uma carga ainda mais pesada para aqueles que deixaram, voluntária ou involuntariamente, suas casas e familiares (SILVA, I.; LUCENA FILHO, 2020; PARISE; CARVALHO; PEREIRA, 2020).

Observa-se nas narrativas as diferentes situaçóes de medo e angústia trazidas, direta ou indiretamente, pela pandemia ou por seus efeitos causados entre a população imigrante e refugiada. 
Quadro 5 - Recortes sobre aspectos psicológicos

\begin{tabular}{|c|l|}
\hline IM017 & $\begin{array}{l}\text { Já tem dos meses que eu não consigo enviar dinheiro a minha família, meu hijos } \\
\text { tiene hambre, fome en Venezuela...eu não sei o que hacer...yo.... eu vim.... pra } \\
\text { buscar uma vida melhor para ellos.... para meu hijo. }\end{array}$ \\
\hline IM027 & $\begin{array}{l}\text { Tengo medo de não poder ficar en Brasil, medo de tener que voltar pra mi país, } \\
\text { porque eu náo consegui trabajo desde que cheguei. }\end{array}$ \\
\hline IM025 & $\begin{array}{l}\text { Eu estou com medo de ficar doenti, porque eu não tenho ninguém aqui comigo, } \\
\text { mia família está no Haiti e precisa di mim. }\end{array}$ \\
\hline IM006 & $\begin{array}{l}\text { É muito difícil esta situação, o dinheiro que eu guardava já acabou e o salão não } \\
\text { voltou a trabalhar, as pessoas tem medo. }\end{array}$ \\
\hline IM023 & $\begin{array}{l}\text { Eu soflo porque eu passo necessidadi aqui e medo que meus filho não tem o que } \\
\text { come no Haiti, mas.... mas........ eu confia em Deus que tudo ..... Ele pode mudá. }\end{array}$ \\
\hline
\end{tabular}

Fonte: Elaborado pela autora, com dados da pesquisa.

Fica evidente o temor entre aqueles mais vulneráveis socialmente, suas angústias por não conseguirem ajudar quem ficou na terra de origem e quem está no país, além do medo por perceberem em perigo a conquista de situaçáo mais favorável de vida. Medos de retrocessos e riscos inerentes à jornada migratória. Esses medos expressam uma infinidade de angústias diante da insegurança, da fome, do desemprego, da falta de abrigo, da doença, da possibilidade de morte, mas, sobretudo, a falta de perspectiva e esperança. Muitas vezes esses indivíduos recorrem à fé religiosa, àquilo que não passa pelas fronteiras racionais: "Deus que tudo ..... Ele pode muda”.

A pandemia de Covid-19 tem mostrado que irá atingir a todos indistintamente; no entanto, as condiçóes de enfrentamento desta realidade sem precedentes não são oferecidas a todos de modo equitativo. É noticiado a todo momento por diferentes meios de comunicação os efeitos da pandemia sobre os mais desfavorecidos e mais pobres, justamente aqueles que mais precisariam ser protegidos, tornando-se a cada dia as vítimas mais frequentes não apenas da pandemia, mas também da desigualdade e da injustiça social.

Neste contexto, a vulnerabilidade social apresenta as faces e interfaces de seu lado mais sombrio, pois os imigrantes e refugiados que vivem em Mato Grosso, além de tantos outros espalhados pelo Brasil, tem, junto a outras minorias, delineado o contorno deste triste mosaico social, agora esfacelado mais ainda pela pandemia. 


\section{Considerações finais}

O fenômeno da imigração como outro fenômeno social não ficou inume a Covid-19, pois estudos sobre os efeitos desta pandemia em relaçáo a população mato-grossense, apesar de muitos ainda estarem em andamento, consideram que o auge da disseminação dessa doença atingiu Mato Grosso em julho de 2020. Neste sentido, levantar informaçóes sobre como e quais os modos de enfrentamento desta pandemia, junto aos que mais necessitam, mostra-se oportuno no sentido de se construir políticas públicas que visem atenuar essa situação.

A situação de vulnerabilidade social, atrelada à população imigrante, agrava-se na medida em que se aumentam as desigualdades sociais e não se desenvolvem políticas públicas capazes de possibilitar alternativas de emprego e renda. Com a pandemia de covid-19, as faces e interfaces da vulnerabilidade social foram ganhando novos rostos e contornos, ou seja, os imigrantes e refugiados passaram a vivenciá-la com maior frequência, compondo os já anteriormente populosos grupos de marginalizados socialmente. Vale ressaltar que a situação de vulnerabilidade social desses grupos vem se agravando com o avanço da pandemia, tanto no Brasil como em outros países do mundo.

Os dados deste estudo possibilitam a percepçáo de que a pandemia de Covid-19 intensificou a situação de vulnerabilidade social de muito imigrantes e refugiados que vivem em Mato Grosso. Eles, que já conviviam com a dificuldade do desaquecimento do mercado formal de trabalho e da escassez de vagas, agora se veem desamparados com a falta de políticas públicas efetivas que lhes garanta condiçôes dignas de acesso a saúde, moradia, emprego e renda, dentre outras limitaçôes impostas pela atual crise sanitária.

Os resultados também atestam que a situação de vulnerabilidade social que acomete a população imigrante e refugiada apresenta diferentes interfaces, tais como: a econômica, marcada pelo aumento do desemprego e dificuldade/ impossibilidade de outras formas de trabalho autônomo; a sanitária, marcada pela impossibilidade de vivenciar o distanciamento e o isolamento social; a jurídica, marcada pela fechamento de fronteiras e fragilidade da condição migratória; a psicológica, marcada pelo medo e angústias do atual cenário de pandemia; dentre outras que não foram neste estudo exploradas.

Essas interfaces da vulnerabilidade social sinalizam nâo apenas categorias, mas demonstram os desafios diários que imigrantes e refugiados enfrentam. Os pedidos de ajuda de grande parte dessa populaçáo têm aumentado com o agravamento da pandemia, já que muitos perderam os postos de trabalho formal 
ou informal, e passaram a depender da solidariedade para sobreviver. A ajuda nas horas de emergência parte de instituiçôes, como o Centro de Pastoral para Migrantes de Cuiabá e de outras frentes sociais e religiosas ou da comunidade mato-grossense em geral.

Dentre as limitaçóes deste estudo, pode-se mencionar a desconfiança por parte dos entrevistados quanto a forma de abordagem e coleta de dados, o que teve impacto significativo sobre o recorte amostral. Diante de tantas questóes suscitadas por este estudo, e considerando o cenário imposto pela pandemia do Covid-19, novas reflexóes no campo da assistência social e de investimentos sociais se fazem necessárias, seja via políticas públicas ou privadas capazes de contemplar estes e outros grupos em situação de vulnerabilidade social, o que seria muito oportuno, tendo em vista o período pós pandemia. Espera-se que as reflexóes aqui tecidas possam auxiliar no desenvolvimento de políticas públicas efetivas para esta população, e que este diagnóstico, ainda que prévio, chame a atenção para o agravamento da situação de vulnerabilidade social dos imigrantes e refugiados que vivem em Mato Grosso.

\section{REFERÊNCIAS}

ALVES, J. F. de S. et al. Utilização de serviços de saúde por imigrantes haitianos na grande Cuiabá, Mato Grosso, Brasil. Ciência \& Saúde Coletiva, Rio de Janeiro, v.24, p. 4677-4686, 2019.

BAENINGER, R. Migração transnacional: elementos teóricos para o debate. In: BAENINGER, R.; PERES, R.; FERNANDES, D.; SILVA, S. A. Imigraçáo haitiana no Brasil. Jundiaí: Paco Editoral, 2016. p.119-143.

BAENINGER, R. et al. Migraçóes sul-sul. Campinas: Núcleo de Estudos de População Elza Berquó-NEPO/UNICAMP, 2018.

BAENINGER, R.; DEMÉTRIO, N. B.; DOMENICONI, J. Imigração internacional na macrometrópole paulista: novas e velhas questôes. Cadernos Metrópole, São Paulo, v.22, n.47, p.17-40, 2020.

BRASIL. Ministério da Justiça e Segurança Pública. Comitê Nacional para os Refugiados- CONARE (2019). Refúgio em números. 4.ed. Brasília: CONARE, 2019. Disponível em: https://www.acnur.org/portugues/wp-content/uploads/2019/07/Refu gio-em-nu\%CC\%81meros_versa\%CC\%83o-23-de-julho-002.pdf. Acesso em: 08 maio 2020. 
BUSSO, G. La vulnerabilidad social y las políticas sociales a inícios del siglo XXI: una aproximación a sus potencialidades y limitaciones para los países latinoamericanos. Santiago do Chile: CEPAL/Celade, 2001.

BRASIL. Polícia Federal. Polícia Federal altera o atendimento do passaporte e aos estrangeiros em virtude da pandemia. O Documento, [s. l.], 24 mar. 2020a. Disponível em: https://odocumento.com.br/policia-federal-altera-o-atendimento-dopassaporte-e-aos-estrangeiros-em-virtude-da-pandemia/. Acesso em: 10 jun. 2020.

BRASIL. Agência Nacional de Vigilância Sanitária. Dispóe sobre a restrição excepcional e temporária de entrada no País de estrangeiros, de qualquer nacionalidade, conforme recomendação da Agência Nacional de Vigilância Sanitária Anvisa. Portaria Interministerial no 340, de 30 de junho de 2020b, Brasília, DF. Disponível em: http://www.in.gov.br/en/web/dou/-/portaria-n-340-de-30-de-junhode-2020-264247695. Acesso em: 07 jul. 2020.

BRASIL. Polícia Federal. Sistema Nacional de Cadastro de Registro de Estrangeiro. Brasília: SINCRE, 2019.

BRASIL. Polícia Federal. Sistema Nacional de Cadastro de Registro de Estrangeiro. Brasília: SINCRE, 2018.

BRASIL. Lei n. 13.445, de 24 de maio de 2017. Institui a Lei de Migração. Diário Oficial da Uniáo, Brasília, DF, 24 maio 2017. Disponível em: http://www.planalto. gov.br/ccivil_03/_ato2015-2018/2017/lei/113445.htm. Acesso em: 06 jun. 2020.

BRASIL. Lei no 9.474, de 22 de julho de 1997. Define mecanismos para a implementação do Estatuto dos Refugiados de 1951, e determina outras providências. Diário Oficial da Uniáo, Brasília, DF, 22 jul. 1997. Disponível em: http://www. planalto.gov.br/ccivil_03/leis/19474.htm. Acesso em: 06 jun. 2020.

DELFIM, R. B. DPU entra em ação contra Caixa e BC para garantir pagamento do auxilio emergencial a imigrantes. 2020. Migramundo, [s. l.], 6 maio 2020. Disponível em: https://www.migramundo.com/dpu-entra-com-acao-contra-caixa-ebc-para-garantir-pagamento-do-auxilio-emergencial-a-imigrantes/. Acesso em: 03 jul. 2020.

FAUGIER, J.; SARGEANT, M. Sampling hard to reach populations. Journal of advanced nursing, Oxford, v.26, n.4, p.790-797, 1997.

GAMA, C. A. P. da; CAMPOS, R. T. O.; FERRER, A. L. Saúde mental e vulnerabilidade social: a direção do tratamento. Revista Latinoamericana de Psicopatologia Fundamental, São Paulo, v.17, n.1, p.69-84, 2014. 
GASKELL, G.; BAUER, M. W. Pesquisa qualitativa com texto, imagem e som: um manual prático. Petrópolis: Vozes, 2002.

GRAY, P. S. et al. The research imagination: an introduction to qualitative and quantitative methods. Cambridge: Cambridge University Press, 2007.

GUIMARÁES, M. A.; ALONSO, K. M. Haitian migration to Brazil: when the racial landscape changes and " $\mathrm{i}$ " and the "other" confront each other in the media and in digital social networks. In: BALTAR, R.; MATEUS, E. (org.). Humanities. São Paulo: Blucher, 2017. p.53-65.

HAGUETTE, T. M. F. Metodologias qualitativas na sociologia. 9.ed. Petrópolis: Vozes, 2003.

HOPKINS, B.; DAWSON, C.; VELIZIOTIS, M. Absence management of migrant agency workers in the food manufacturing sector. The International Journal of Human Resource Management, London, v.27, n.10, p.1082-1100, 2016.

INOUYE, K. et al. Percepçóes de suporte familiar e qualidade de vida entre idosos segundo a vulnerabilidade social. Psicologia: reflexão e crítica, Porto Alegre, p.582$592,2010$.

INTERNATIONAL ORGANIZATION FOR MIGRATION (IOM). Migration Data Portal: the bigger picture. Berlin: IOM, 2020. Disponível em: https:// migrationdataportal.org/ data?i=stock_abs_\&t=2019. Acesso em: 04 maio 2020.

INTERNATIONAL ORGANIZATION FOR MIGRATION (IOM). World Migration Report 2020. Geneva: IOM, 2019. Disponível em: iom.int/wmr. Acesso em: 07 jul. 2020.

KLUGE, H. H. P. et al. Refugee and migrant health in the COVID-19 response. The Lancet, London, v.395, n.10232, p.1237-1239, 2020.

LEÂO, L. H. D. C. et al. The health of Haitian immigrant workers in Mato Grosso, Brazil: vulnerabilities and risks. Salud colectiva, Lanus, v.14, n.4, p.779-795, 2018.

LEÃO, L. H. da C. et al. International migration, health, and work: an analysis of Haitians in Mato Grosso State, Brazil. Cadernos de Saúde Pública, Rio de Janeiro, v.33, n.7, 2017. Disponível em: https:/www.scielo.br/j/csp/a/Kq4zLH8G36sWvqLJ pLSLFrz/?lang=pt\&format=pdf. Acesso em: 08 set. 2021.

MATOS, R.A contribuição dos imigrantes em áreas de desconcentração demográfica do Brasil contemporâneo. Revista Brasileira de Estudos de Populaçáo, Campinas, v.19, n.1, p.49-74, 2013. 
MARIZ, L. A. et al. O reinado dos estudos de caso na teoria das organizaçóes: imprecisôes e alternativas. Cadernos Ebape, Rio de Janeiro, v.3, n.2, p.01-14, 2005.

MARTUSCELLI, P. N. How are refugees affected by Brazilian responses to COVID-19? Revista de Administraçáo Pública, Rio de Janeiro, v.1, n.17, p.01-12, 2020 .

MATHIS, A. Cadastro único, espelho da pobreza e vulnerabilidade social no Pará, e as possibilidade de seu uso como instrumento de gestáo no combate da pandemia de Covid-19. Papers do NAEA, Belém, v.29, n.1, p.132-169, 2020.

MATTOS, P. Migração e refúgio em contexto da pandemia. In: FÓRUM NACIONAL DE DIREITOS HUMANOS DA AJUFE, 2., 2020, Brasília. Publicado pelo canal AJUFE. Disponível em: https://www.youtube.com/watch?v= CRjm7PZvbGk. Acesso em: 29 maio 2020.

ORCUTT, M. et al. Global call to action for inclusion of migrants and refugees in the COVID-19 response. The Lancet, London, v.395, n.10235, p.1482-1483, 2020.

PARISE, P. Impactos econômicos da imigração a partir da experiência da Missão de Paz. Revista Diálogos estratégicos: migraçôes e seus impactos na sociedade do século XXI, Brasília, v.1, n.4, 2018. Disponível em: https://www.gov.br/secretariageral/pt-br/ centrais-de-conteudo/publicacoes/publicacoes-e-analise/revista-dialogos-estrategicos. Acesso em: 08 set. 2021.

PARISE, P.; CARVALHO, L.; PEREIRA, J. C. Missão Paz: assistência, formação e incidência social versus o negativismo de direitos a migrantes e refugiados na interface da Covid-19. In: BAENINGER R.; VEDOVATO, L. R.; NANDY, C. (coord.). Migraçóes internacionais e a pandemia de Covi1-19. Campinas: Núcleo de estudos de população Elza Berquó, 2020. p.79-92.

PATARRA, N.; FERNANDES, D. Políticas públicas e migração internacional no Brasil. In: CHIARELLO, L. M. (coord.). Las Políticas Públicas sobre Migraciones y La Sociedad Civil en América Latina. São Paulo: Scalabrini International Migration Network, 2011. p.151-276.

PELLIZARI, K.; MAZARO, R. E. Políticas de inserção social de migrantes no mercado de trabalho mato-grossense: um processo em construção. In: SEMINÁRIO EM ADMINISTRAÇÃO PPGA/FEA/USP-SEMEAD, 2018, São Paulo. Anais [...]. São Paulo: FEA, 2018. Disponível em: https://login.semead.com.br/20semead/anais/ arquivos/965.pdf. Acesso em: 09 set. 2021.

PELLIZARI, K. O jogo de poder entre os atores sociais coletivos e os imigrantes nas cidades de Cuiabá e Sáo Paulo. Tese (Doutorado em Administração) - Pontifícia Universidade Católica de Minas Gerais, Minas Gerais, 2019. 
PELLIZARI, K.; ROQUE-FARIA, H. J. A língua portuguesa como instrumento de acesso ao mercado de trabalho: imigrantes no norte de mato grosso. Revista Expectativa, [s.l.], v.16, n.2, p.167-189, 2017.

PORTO, M. F. No meio da crise civilizatória tem uma pandemia: desvelando vulnerabilidades e potencialidades emancipatórias. Revista Visa em Debate, Rio de Janeiro, v.8, n.3, p.2-10, 2020.

PRATI, L. E.; COUTO, M. C. P.; KOLLER, S. H. Famílias em vulnerabilidade social: rastreamento de termos utilizados por terapeutas de família. Psicologia: teoria e pesquisa, Brasília, v.25, n.3, p.403-408, 2009.

RIAÑO, Y.; PIGUET, E. International Student Migration. Oxford: Oxford University Press, 2016. (Oxford Bibliographies).

SALGANIK, M. J.; HECKATHORN, D. D. Sampling and estimation in hidden populations using respondent-driven sampling. Sociological methodology, Oxford, v.34, n.1, p.193-240, 2004.

SANTOS, J. de O. Relaçóes entre fragilidade ambiental e vulnerabilidade social na susceptibilidade aos riscos. Mercator, Fortaleza, v.14, n.2, p.75-90, 2015.

SILVA, I. L.; LUCENA FILHO, E. L. Saúde mental e assistência social: desafios durante a COVID-19. Revista Psicologia \& Saberes, Maceió, v.9, n.19, p.138-146, 2020 .

SILVA, S. B.; RAPOPORT, A. Desempenho escolar de crianças em situação de vulnerabilidade social. Revista Educação em Rede, Cachoeirinha, 2013. Disponível em: http://ojs. cesuca. edu. br/index. php/educacaoemrede/index. Acesso em: 20 jul. 2016.

STEFANELLI, M. M. C.; BASTOS, S. Missão Paz: lugar de hospitalidade e acolhimento aos I-Migrantes em São Paulo, SP. Rosa dos Ventos: Turismo e Hospitalidade, Caxias do Sul, v.8, n.3, p.256-273, 2016.

TANNOCK, S. Bad attitude? migrant workers, meat processing work and the local unemployed in a peripheral region of the UK. European Urban and Regional Studies, Harlow, v.22, n.4, p.416-430, 2015.

TEIXEIRA, I. N. D. Definiçóes de fragilidade em idosos: uma abordagem multiprofissional. Dissertação (Mestrado em Gerontologia) - Faculdade de Educação, Universidade Estadual de Campinas, Campinas, 2006.

TOPA, J.; NEVES, S.; NOGUEIRA, C. Imigração e saúde: a (in) acessibilidade das mulheres imigrantes aos cuidados de saúde. Saúde e Sociedade, São Paulo, v.22, p.328-341, 2013. 
UNITED NATIONS HIGH COMMISSIONER FOR REFUGEES (UNHCR). Global Trends forced displacement in 2019. Genebra: UNHCR, 2020. Disponível em: https://www.unhcr.org/5ee200e37/\#_ga= 2.199139439.1524817274.1593784 772-1287123496.1585343056. Acesso em: 01 jul. 2020.

VERGARA, S. C. Métodos de pesquisa em administraçáo. São Paulo: Atlas, 2005.

WORLD HEALTH ORGANIZATION (WHO). How WHO is supporting refugees and migrants during the COVID-19 pandemic. 2020. Disponível em: https://www.who.int/news-room/feature-stories/detail/how-who-is-supportingrefugees-and-migrants-during-the-covid-19-pandemic. Acesso em: 18 maio 2020.

Recebido em: 06 de agosto de 2021

Aprovado em: 31 de outubro de 2021 